\title{
Management of Lacrimal Fistula during Epicanthoplasty: A Case Report
}

\author{
Hyun Ho Han', Hyo Wan Suh', \\ Nam Ho Kim ${ }^{3}$, Ro Hyuk Park ${ }^{3}$, \\ Kyun Tae $\mathrm{Kim}^{3}$, Tae Joo $\mathrm{Ahn}^{3}$ \\ ${ }^{1}$ Department of Plastic Surgery, Asan \\ Medical Center, University of Ulsan \\ College of Medicine, Seoul; ${ }^{2}$ Department \\ of Plastic and Reconstructive Surgery, \\ College of Medicine, The Catholic \\ University of Korea, Seoul; ${ }^{3}$ Gyalumhan \\ Plastic Surgery, Seoul, Korea
}

No potential conflict of interest relevant to this article was reported.

\begin{abstract}
Lacrimal fistula (LF) is a rare abnormality of the lacrimal system. Patients with LF are usually asymptomatic, and thus, treatment is unnecessary. During surgery on a patient with LF, the fistula may fall into the range of dissection. In such cases, fistula management becomes important. A 19-year-old woman visited our department to receive incisional blepharoplasty and medial epicanthoplasty, and a preoperative physical examination revealed LF. During surgery, we found the fistula tract to be within the dissection field, and thus, the LF was cut and cauterized. One year after the surgery, inflammation and hypertrophy of the remnant lacrimal duct occurred. The wound was stabilized by creating an opening that reconnected the stump and the overlying skin. Through this case, we hope to establish the appropriate strategy for managing LF detected during medial epicanthoplasty. As seen in our case, cauterization should be avoided because of the high recurrence rate of LF. Instead, as definitive treatment, fistulectomy should be performed, or the fistula should be moved along with the skin flap when a small skin flap is transferred.
\end{abstract}

Keywords Blepharoplasty, Fistual, Lacrimal appratus disase

\section{INTRODUCTION}

Lacrimal fistulas (LFs), also known as lacrimal anlage ducts, are supernumerary lacrimal canaliculi that connect the skin to the common canaliculus or the lacrimal sac $[1,2]$. In some cases, these may result from a secondary cause. However, most cases are congenital; therefore, congenital LF is the most accurate term for this condition [1]. The incidence of congenital LF is estimated to be 1 in 2000 births, and occasionally LF can be inherited in an autosomal dominant or autosomal recessive pattern [3-5]. LF is mostly unilateral and situated inferonasally from the medial canthus [6]. Some symptomatic cases may present with epiphora, blepharitis, or recurrent dacryocystitis, but most cases are asymptomatic, mak-

Received: Apr 7, 2017 Revised: Apr 24, 2017 Accepted: Apr 24, 2017

Correspondence: Tae Joo Ahn Gyalumhan Plastic Surgery, 21st Mijinplaza, 390 Gangnam-daero, Gangnam-gu, Seoul 06232, Korea.

E-mail:cmcanti@hanmail.net

Copyright @ 2017 The Korean Society for Aesthetic Plastic Surgery.

This is an Open Access article distributed under the terms of the Creative Commons Attribution Non-Commercial License (http://creativecommons.org/licenses/by-nc/4.0/) which permits unrestricted non-commercial use, distribution, and reproduction in any medium, provided the original work is properly cited. www.e-aaps.org ing treatment unnecessary [6]. Therefore, most patients with LF tend not to seek medical treatment for LF, unless they recognize that they have this condition.

Medial epicanthoplasty is a widely performed surgical procedure in East Asians because of their small and narrow nasal scleral triangle and their preference for large, balanced eyes. Medial epicanthoplasty using the skin redraping method introduced by Oh et al. [7] in 2007 is one of the most widely performed surgical methods. When carrying out this procedure on a patient with LF, the fistula may be included in the dissection range. In such cases, fistula management becomes important.

Herein, we introduce the case of a patient with LF that was found during medial epicanthoplasty and its management.

\section{CASE}

A 19-year-old woman visited our department to receive incisional blepharoplasty and medial epicanthoplasty. LF was found during a preoperative physical examination; it was located inferonasally from the medial canthus (Fig. 1). The patient did not exhibit any symptoms, including epiphora, mucoid discharge, or dacryocystitis. She underwent medial epicanthoplasty using the skin redraping 

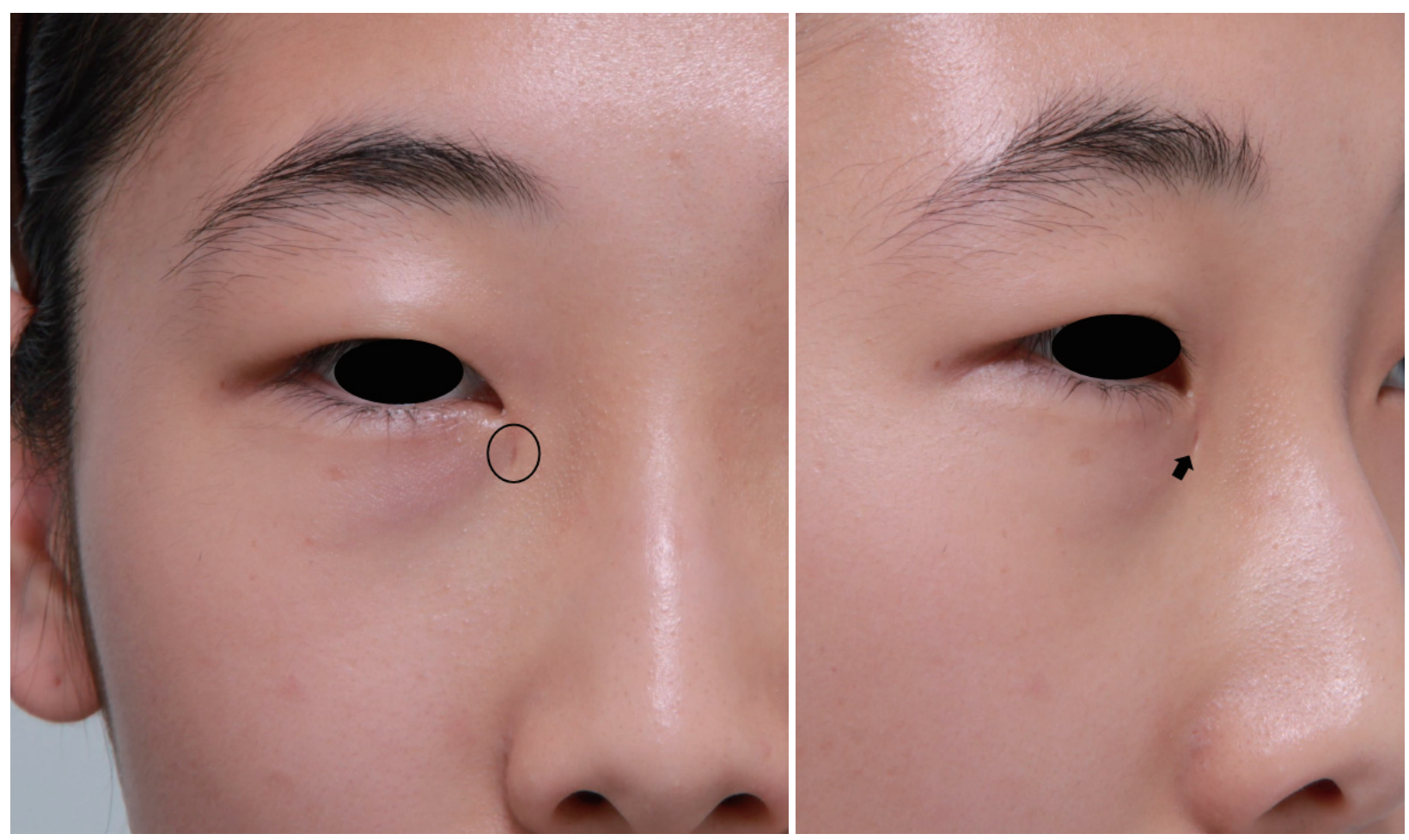

Fig. 1. A 19-year-old female visited our clinic to receive blepharoplasty and medial epicanthoplasty. A lacrimal fistula was found incidentally; it was located inferonasally from the medial canthus.

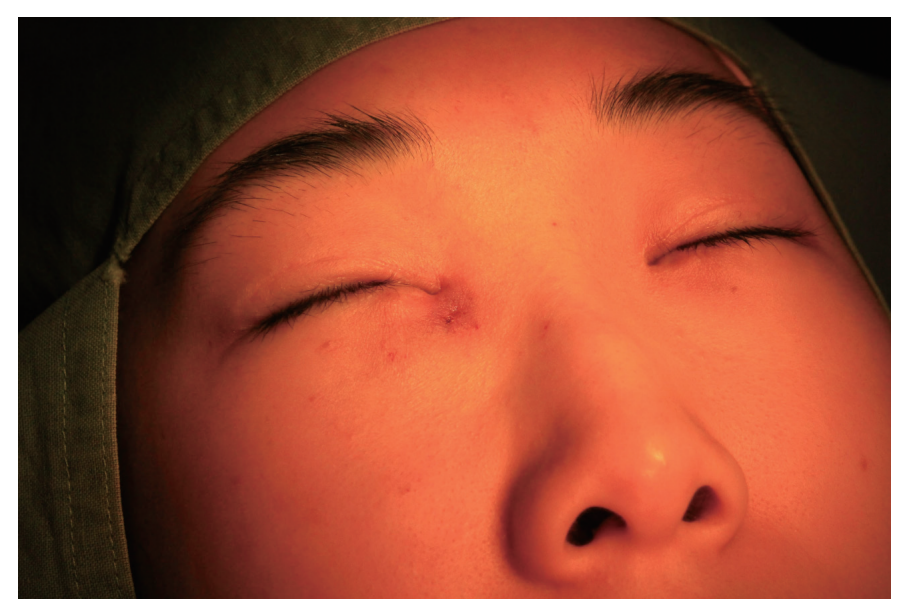

Fig. 2. The lacrimal fistula was cut and cauterized during the operation. One year after surgery, inflammation occurred in the remaining lacrimal duct.

method. During skin elevation in the midst of surgery, the fistula tract was detected. We cut off the fistula connected to the skin, and then cauterized the stump. Skin redraping and closure followed. However, 1 year after surgery, inflammation occurred in the same uneven area (Fig. 2). Moreover, hypertrophy of the remnant lacrimal duct occurred. Temporary improvement was observed upon the creation of an opening in the inflamed area followed by the administration of antibiotics, but the patient's condition soon wors-

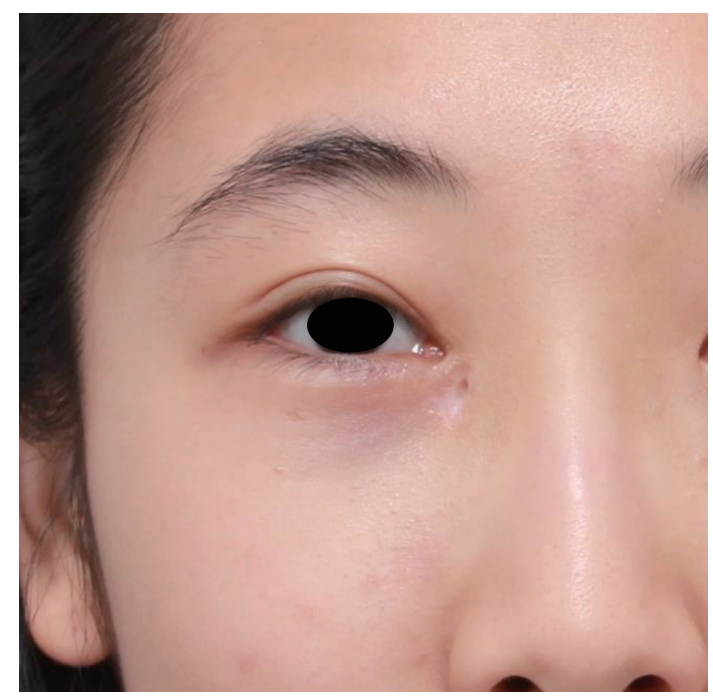

Fig. 3. A fistula opening that connected the stump and the overlying skin was made 13 months postoperatively. The patient's remained stable after this procedure over the course of 16 months of follow-up.

ened. Thirteen months postoperatively, we created a fistula opening that reconnected the stump and the overlying skin. The wound remained stable over the course of 16 months of follow-up after this procedure (Fig. 3). 


\section{When lacrimal fistula is confirmed}

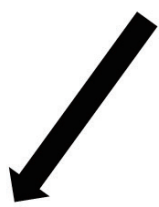

Fistulectomy

(distal orifice dissection $\&{ }^{\text {al }}$ tie)

Fig. 4. Treatment algorithm for lacrimal fistula. al Cauterization should be avoided.

\section{DISCUSSION}

In addition to the rarity of LF, most patients with LF tend to be asymptomatic, which makes it difficult to detect this condition. The classification of congenital LF is based on the origin of its tract, which may be the common canaliculus, lacrimal sac, or the nasolacrimal duct [8]. If it originates from the common canaliculus or lacrimal sac, the fistula could be included in the skin flap during medial epicanthoplasty.

If LF is discovered during a preoperative physical examination, a diagnostic investigation is needed to accurately evaluate and detect its origin [8]. In adults, probing of the fistula or lacrimal irrigation to check for pharyngeal drainage is sufficient for a definitive diagnosis. However, a non-invasive test such as a fluorescein dye disappearance test is needed for evaluating children who cannot undergo invasive tests. If the dye stays in the eye, the duct can be considered blocked [9]. When conducting medial epicanthoplasty, it is preferable to detect the fistula by preoperative history-taking and a physical examination.

There are 2 ways to manage a fistula discovered within the dissection range during the medial epicanthoplasty procedure (Fig. 4). The definitive treatment is fistulectomy, which involves dissecting the tissue around the distal orifice of the fistula tract followed by tying the opening and separating the skin flap [6]. Since tying the opening of the fistula can sometimes block normal lacrimal drainage, one needs to check the patency of the normal lacrimal system by probing or irrigation after the procedure. When a small skin flap needs to be transferred during the medial epicanthoplasty, the opening of the fistula can be moved along with the skin flap [6]. In either case, it is extremely important to avoid only cutting or cauterizing the fistula tract because of the high recurrence rate of LF $[6,8]$.

In conclusion, $\mathrm{LF}$ is an uncommon disease entity that physicians may encounter in clinical practice. Without prior background, not knowing how to manage this condition could be embarrassing. When LF is found during medial epicanthoplasty, the surgeon should not simply cut or cauterize the fistula tract because of the high recurrence rate of LF. Instead, fistulectomy should be preferentially considered, and the fistula can be moved along with the skin flap if a small skin flap is necessary for the transfer.

\section{PATIENT CONSENT}

Patients provided written consent for the use of their images.

\section{REFERENCES}

1. Welham RA, Bergin DJ. Congenital lacrimal fistulas. Arch Ophthalmol 1985;103:545-8.

2. Birchansky LD, Nerad JA, Kersten RC, et al. Management of congenital lacrimal sac fistula. Arch Ophthalmol 1990;108:388-90.

3. François J, Bacskulin J. External congenital fistulae of the lacrimal sac. Ophthalmologica 1969;159:249-61.

4. Zhuang L, Sylvester CL, Simons JP. Bilateral congenital lacrimal fistulae: a case report and review of the literature. Laryngoscope 2010;120 Suppl 4:S230.

5. Maden A, Yilmaz S, Ture M. Hereditary lacrimal fistula. Orbit 2008; 27:69-72.

6. Chaung JQ, Sundar G, Ali MJ. Congenital lacrimal fistula: A major review. Orbit 2016;35:212-20.

7. Oh YW, Seul CH, Yoo WM. Medial epicanthoplasty using the skin redraping method. Plast Reconstr Surg 2007;119:703-10.

8. Toda C, Imai K, Tsujiguchi K, et al. Three different types of congenital lacrimal sac fistulas. Ann Plast Surg 2000;45:651-3.

9. Nagaraju G, Samhitha HR, Chhabria KP, et al. Efficacy of fluorescein dye disappearance test in the diagnosis of lacrimal system outflow obstruction. J Evid Based Med Healthc 2015;2:1377-86. 